\title{
SIFAT AMANAH KARYAWAN MASJID CHENG HOO SURABAYA ${ }^{1}$
}

\author{
Lestari Dwi Astuti \\ Departemen Ekonomi Syariah-Fakultas Ekonomi dan Bisnis-Universitas Airlangga \\ Email: lestari.dwi.astuti-2014@feb.unair.ac.id \\ Sri Herianingrum \\ Departemen Ekonomi Syariah-Fakultas Ekonomi dan Bisnis-Universitas Airlangga \\ Email: sriheria@gmail.com
}

\begin{abstract}
:
The Mosque is a place of worship for Muslims. Employees are needed for managing and maintaining Mosques. Working in a Mosque must have a amanah so that employees can be trusted in the continuity of the tasks that have been done. The aims of this study was to find out how the implementation of the amanah of the employees on Cheng Hoo Surabaya Mosque. This study uses descriptive eksplanatoris methods. This study uses interviews and primary data collection. For informants the amanah can show prosperity to itself. Needs will be fulfilled if working with sincerity and amanah. For informants, Economic Indicators that are accepted by Cheng Hoo Mosque employees are sufficient because for the employees of the Cheng Hoo Mosque, the first one is seeking Allah's blessing, not only worldly.
\end{abstract}

\section{Keywords: Implementation, Amanah, Mosque, Employees.}

\section{PENDAHULUAN}

Masjid merupakan institusi keagamaan yang tidak terpisahkan dari kehidupan spiritual, sosial, dan kultural serta menjadi pusat kehidupan muslim. Secara teori, Masjid merupakan pusat kebudayaan Islam dan merupakan tempat ibadah umat muslim. Masjid berasal dari kata sajada yang artinya tempat bersujud (Kusumawardhani,2011).

Di Indonesia memiliki ribuan Masjid yang tersebar di bebagai penjuru Nusantara. Di Kota Surabaya sendiri juga memiliki banyak Masjid, tetapi ada salah Masjid yang memiliki ciri khas yang berbeda dari Masjid lainnya yaitu yang bernama Masjid Cheng Hoo Surabaya. Masjid cheng hoo merupakan wisata religi di Surabaya dan memiliki arsitektur yang unik dan berciri khas Tiongkok.

Sifat amanah artinya jujur atau dapat di percaya. Menurut istilah Sifat amanah merupakan suatu sifat tulus hati dan jujur dalam melaksanakan sesuatu yang telah dipercayakan kepadanya berupa harta benda maupun tugas yang telah menjadi kewajibannya.

Dalam pemeliharaan Masjid di perlukan karyawan untuk pengembangan masjid. Selain itu karyawan harus memiliki sifat amanah. Sifat amanah diperlukan karyawan untuk menjalankan tugastugasnya yang nantinya akan menentukan gaji yang sesuai dengan apa yang dikerjakan. Sehingga kesejahteraan akan dapat tercapai dengan sendirinya.

\footnotetext{
${ }^{1}$ Jurnal ini merupakan bagian dari skripsi Lestari Dwi Astuti, NIM: 041411431123, yang diuji pada tanggal 23 Januari 2019.
} 
Tujuan Syariah yang dimaksud tentunya bahwa, jika seseorang yang bekerja harus melaksanakan aktivitas dan tugasnya sehari-hari, tidak boleh bertentangan dengan syariat Islam (Konsep maqashid syariah).

Penelitian ini dibuat untuk mengetahui bagaimana sifat amanah karyawan masjid cheng hoo Surabaya, sehingga dapat diambil manfaat yang mungkin berguna untuk orang lain.

\section{LANDASAN TEORI}

Masjid merupakan tempat ibadah umat Islam (muslim). Secara harfiah, masjid berasal dari Bahasa Arab yaitu sajada,yasjudu,sujudan. Dari akar kata tersebut maka terbentuklah kata Masjid yang berarti tempat sujud. Sujud adalah rukun shalat, sebagai bentuk ikhtiar hambahnya dalam mendekatkan diri pada Allah SWT. Masjid perlu adanya Pemeliharaan. Pemeliharaan Masjid sangat diperlukan karena berperan penting dalam mencangkup keseluruhan isi Masjid. Pemeliharaan Masjid dilakukan agar Masjid menjadi nyaman untuk tempat beribadah.

Masjid Cheng HoO, merupakan sebuah Masjid yang berciri khas tiongkok. Salah satu keunikan dari bangunan Masjid Cheng Hoo adalah tidak memiliki pintu Masjid, sebagaimana Masjid yang sering ditemui pada umumnya. Hal ini menunjukkan bahwa Masjid Cheng Hoo terbuka bagi siapa saja, dari ras manapun, agama manapun, dan tidak memihak pada aliran manapun. Masjid
Cheng hoo merupakan Masjid Perdana di Surabaya sebagai peradaban budaya masyarakat tionghoa.

Dalam pemeliharaan Masjid di perlukan adanya karyawan. Karyawan dapat diartikan sebagai setiap orang yang memberikan jasa kepada perusahaan ataupun organisasi yang membutuhkan jasa tenaga kerja, yang mana dari jasa tersebut karyawan akan mendapatkan gaji dan kompensasikompensasi lainnya.

Karyawan harus memiliki sifat amanah Amanah adalah janji atau titipan dan sesuatu yang dipercayakan kepada seseorang. Amanah adalah segala bentuk kepercayaan yang diberikan kepada seseorang, baik dalam bentuk perintah maupun larangan, baik terkait urusan ukhrawi, sehingga semua syariat Allah adalah amanah. Amanah bisa datang dari Allah swt. Sebagaimana yang dipaparkan dalam QS. al-Ahzab: 72:

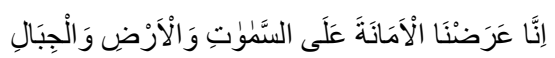

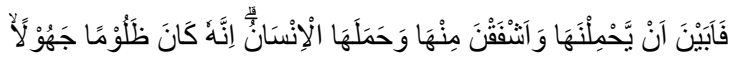
Artinya: "Sesungguhnya Kami telah menawarkan amanat kepada langit, bumi dan gunung-gunung; tetapi semuanya enggan untuk memikul amanat itu dan mereka khawatir tidak akan melaksanakannya (berat), lalu dipikullah amanat itu oleh manusia. Sungguh, manusia itu sangat zalim dan sangat bodoh,"

Sehingga sifat amanah harus dimiliki oleh karyawan agar karyawan dapat 
dipercaya dalam kelangsungan tugas yang telah dikejakan.

$$
\text { Mujib (2007:185) mengatakan }
$$

bahwa kata amanah berasal dari akar kata yang sama dengan iman dan aman. Artinya orang yang amanah berarti orang memiliki rasa iman yang kuat yang akhirnya akan mendatangkan kehidupan yang aman, sebab ia telah mampu menunaikan segala kepercayaan yang di emban.

\section{Ahmad Musthafa Al-Maraghi} membagi amanah kepada 3 macam, yaitu:

1. Amanah manusia terhadap Tuhan, yaitu semua ketentuan Tuhan yang harus dipelihara berupa melaksankan semua perintah Tuhan dan meninggalkan semua larangannya. Termasuk di dalamnya menggunakan semua potensi dan anggota tubuh untuk hal-hal yang bermanfaat serta mengakui bahwa semua itu berasal dari Tuhan. Sesungguhnya seluruh maksiat adalah perbuatan khianat kepada Allah.

2. Amanah manusia kepada orang lain, diantaranya mengembalikan titipan kepada yang mempunyainya, tidak menipu dan berlaku curang, menjaga rahasia dan semisalnya yang merupakan kewajiban terhadap keluarga, kerabat dan manusia secara keseluruhan. Termasuk pada jenis amanah ini adalah pemimpin berlaku adil terhadap masyarakatnya, ulama berlaku adil terhadap orang-orang awam dengan memberi petunjuk kepada mereka untuk memiliki i'tikad yang benar, memberi motivasi untuk beramal yang memberi manfaat kepada mereka di dunia dan akhirat, memberikan pendidikan yang baik, menyuruh berusaha yang halal serta memberikan nasihat-nasihat yang dapat memperkokoh keimanan agar terhindar dari segala kejelekan dan dosa serta mencintai kebenaran dan kebaikan.

3. Amanah manusia terhadap dirinya sendiri, yaitu berbuat sesuatu yang terbaik dan bermanfaat bagi dirinya baik dalam urusan agama maupun dunia, tidak pernah melakukan yang membahayakan dirinya di dunia dan akhirat.

$$
\text { Indikator amanah Menurut }
$$
Tasmara (2001:232) adalah tanggung jawab, tepat janji, sertatransparan.

1. Tanggung Jawab

Tanggung jawab dapat diartikan sebagai sikap dan tindakan seseorang di dalam menerima sesuatu sebagai amanah dengan penuh rasa cinta menunaikannya dalam bentuk amalamal shaleh (Tasmara, 2001:2).Tanggung jawab dalam hal pengelolaan yang dipikul oleh manusia untuk mengelola bumi ini adalah dengan menerapkan amanah sebagai tuntutan syariat di dalam pengelolaan bumi untuk kesejahteraan dan keamanan seluruh makhluk diatas bumu (Jauhari, 2006:297). Rasa 
tanggung jawab (takwa), merupakan salah satu aktualisasi diri untuk mewujudkan hasil yang optimal atau islah (Tasmara, 2006:222). Sehingga sikap yang harus dilakukan oleh karyawan adalah untuk memakmurkan Masjid.

2. Tepat Janji

Tepat janji menurut Tasmara (2006:232) merupakan key informance Indicator dalam amanah. Sikap amanah dan tepat janji, adalah dua sifat yang saling berkaitan, apabila ada amanah pasti ada sikap menepati janji, jika satu sifat hilang maka akan hilang pula sikap yang lainnya. Tepat janji sangat berhubungan dengan lisan atau ucapan, sehingga apabila seseorang berucap janji maka sebaiknya menepatiya. Seseorang yang mampu menepatinya maka mereka itu termasuk orang yang menjaga amanah. Apabila amanah tersebar dalam masyarakat, maka jalinan antar mereka akan menjadi agung, pertaliannya akan menjadi kokoh serta kebaikan dan berkah akan meliputinya. Penerapan tepat janji merupakan dari amanah dalam penerapannya dalam penerapannya di lingkup masjid dapat dilakukan dengan menepati janji kerja yang dilakukan di awal sehingga menghasilkan komitmen kerja yang tinggi dan hasilmaksimal.

3. Transparansi
Transparan dapat diartikan terbuka, terbuka dalam artian melaporkan segala kegiatan baik ke public maupun kepada atasan. Tidak pernah mengkomesilkan jabatan atau memanipulasi dan memanfaatkan juga merupakan pedoman bersikap dan bertingkah laku berdasarkkan amanah (Tasmara, 2006:236).

Dengan Memiliki sikap mental yang amanah akan terjalin sikap saling percaya, positif thinking, jujur dan transparan dalam seluruh aktifitas kehidupan yang pada akhirnya akan terbentuk model masyarakat yang ideal yaitu masyarakat aman, damai sejahtera. Sehingga menjadikan transparan juga bagian dari sifat amanah. Transparansi sangat perlu dilakukan oleh setiap orang agar tidak akan menimbulkan rasa suudzon atar sesama manusia. Transparansi dilakukan oleh karyawan agar menghasilkan rasa nyaman antar sesama pekerja. Selain itu karywan Masjid juga harus melakukan transparansi terhadap perolehan infaq, shodaqoh, maupun zakat kepada jamaah masjid.

Maqashid Syariah merupakan tujuan yang ingin di capai setiap penetapan hukum islam oleh Allah SWT dan Rasulnya. Maqashid Syariah adalah tujuan-tujuan syariat dan rahasia-rahasia yang dimaksudkan oleh Allah dalam setiap hukum dari keseluruhan hukumnya. Inti dari tujuan Syariah adalah merealisasikan kemaslahatan bagi manusia dan menghilangkan 
kemudharatan, sedangkan maba'di (pokok dasar) yaitu memperhatikan nilainilai dasar Islam, seperti keadilan, persamaan dan kemerdekaan.

Maqashid Syariah merupakan sesuatu yang penting demi terwujudnya kemaslahatan agama dan dunia. Apabila hal tersebut tidak terwujud maka akan menimbulkan kerusakan bahkan hilangnya hidup dan kehidupan. Hakikat dari maqashid adalah kemaslahatan.

1. Memelihara Agama (Hifdzud Din)

Agama merupakan pedoman hidup manusia yang harus tetap dijaga sesuai dengan ajaran nya. Setiap Agama berhak atas agamanya dan tidak boleh dipaksa untuk meninggalkan agamanya, juga tidak boleh dipaksa untuk berpindah keyakinan untuk masuk Islam.

2. Memelihara Jiwa (Hifdzud Nafs)

Allah mensyariatkan pernikahan dan melanjutkan keturunan untuk melestarikan ras manusia. Sehingga dalam islam mewajibkan makan, minum, pakaian dan lain-lainnya untuk menjamin kehidupan manusia (Duhriah,2015).

3. Memelihara Akal (Hifdzud Aql)

Akal merupakan karunia dari Allah yang sangat berharga, sehingga manusia diwajibkan untuk menjaga dan tidak boleh mengkonsumsi segala hal yang dapat merusak akal kita.

4. Memelihara kehormatan dan keturunan (Hifdzud Nasl)
Disyariatkan menikah untuk memperbanyak keturunan, kemudian syariat menjaga dengan menjauhi halhal yang menjerumuskan ke zina. Begitupula dengan di haramkannya menuduh wanita-wanita yang baik dengan tuduhan zina.

5. Memelihara Harta (Hifszud Maal)

Syariat membolehkan segala jenis muamalah yang sesuai dengan kaidah syariat islam. Wajib berusaha untuk memenuhi kebutuhan hidup, syariat juga menjaga harta dengan mengharamkan mencuri dan menghilangkan harta orang lain.

\section{METODE PENELITIAN}

\section{Pendekatan Penelitian}

Pendekatan penelitian yang digunakan untuk meneliti mengenai Implementasi kesejahteraan karyawan prespektif maqashid syariah pada Masjid Cheng Hoo Surabaya adalah dengan menggunakan pendekatan penelitian kualitatif. Menurut Yin (2015:2), pendekatan kualitatif adalah pendekatan dengan menggunakan data yang berupa kalimat tertulis ataupun lisan, peristiwaperistiwa, pengetahuan, atau proyek studi yang bersifat deskriptif.Menurut Yin (2015:1), Studi kasus merupakan strategi yang cocok untuk tipe pertanyaan dalam penelitian berupa pertanyaan "how" atau "why", selain itu peneliti memiliki sedikit peluang untuk melakukan control terhadap peristiwa yang akan di teliti, dan fokus penelitiannya terletak pada fenomena masa kini di dalam konteks 
kehidupan nyata (Yin, 2015:1). Jenis studi kasus yang digunakan dalam penelitian ini adalah studi kasus Eksplanatoris yang menjelaskan hubungan kausal dalam konteks kehidupan nyata.

\section{Jenis dan Sumber Data}

Data merupakan hal yang sangat penting dalam sebuah penelitian. Jika dalam penelitian tidak memiliki data, maka penelitian tersebut tidak akan berjalan dengan semestinya. Data yang digunakan dalam penelitian ini terdiri dari dua sumber jenis data, yaitu:

1. Data Primer

Merupakan data yang diperoleh melalui wawancara maupun memberikan daftar pertanyaan. Wawancara dilakukan kepada Karyawan pada Masjid Cheng Hoo Surabaya. Wawancara si peneliti kepada informan dengan memberikan pertanyaan-petanyaan mengenai penerapan kesejahteraan karyawan pada Masjid Cheng Hoo Surabaya.

2. Data Sekunder

Merupakan data yang mendukung sebuah penelitian, yang didapatkan secara tidak langsung yang berupa arsip, laporan, dan dokumen yang relevan serta kajian pustaka yang berkaitan dengan penelitian. Data sekunder dalam penelitian ini dapat diperoleh dari buku, jurnal, surat kabar, majalah, dokumen atau laporan kegiatan penelitian yang pernah dilakukan yang terkait dengan implementasi sifat amanah karyawan
Masjid Cheng Hoo Surabaya dalam mewujudkan perspektif Maqashid Syariah.

\section{Prosedur Pengumpulan data}

Menurut Yin (2015:103) bahwa terdapat enam sumber yang dapat dijadikan fokus pengumpulan data studi kasus nya adalah: dokumen, rekaman arsip, wawancara, observasi langsung, observasi pemern serta perangkat fisik. Teknik pengumpulan data yang digunakan dalam penelitian ini adalah:

a. Wawancara: Sebelum melakukan wawancara peneliti terlebih dahulu menyiapkan surat permohonan yang ditunjukkan kepada masjid Cheng HoO Surabaya.

b. Dokumen: dipilih Karena dokumen ini dapat memperkuat data-data yang ditemukan dilapangan sehingga dokumen tersebut dapat lebih kuat pembuktiannya.

c. Rekaman Arsip: Penelitian ini menggunakan rekaman arsip, Karena dapat menjadi pendukung dan penguat penelitian ini. Rekaman arsip dapat berbentuk rekaman keorganisasian, serta denah masjid cheng hoo Surabaya dan rekaman pribadi.

d. Observasi langsung: Observasi langsung dapat dilakukan selama melaksanakan kunjungan lapangan termasuk dapat mengumpulkan buktibukti yang lain seperti pada wawancara. Bukti observasi seringkali bermanfaat dapat memberikan 
informasi tambahan tentang topik yang akan diteliti.

\section{Teknik Analisis}

Penelitian ini menggunakan pembuatan eksplanasi, Karena dalam penelitian ini menggunakan dua variabel. Metode eksplanasi adalah suatu metode penelitian yang menggambarkan dua variabel yang diteliti, yaitu variable bebas dan variabel terikat yang kemudian menjelaskan hubungan atau pengaruh kedua variabel tersebut. Yin (2015:147) mengatakan pada studi-studi kasus yang ada, pembuatan eksplanasi sering di gunakan dalam bentuk naratif. Karena narasi itu tidak bisa sama persis, studi kasus-studi kasus yang baik adalah eksplanasinya mencerminkan beberapa proporsi yang signifikan secara teoristis.

Pembuatan penjelasan digunakan untuk mengetahui implementasi sifat amanah pada karyawan masjid cheng hoo Surabaya sudah termasuk dalam indikator indikator yang di gunakan dalam penelitian ini atau belum. Data di dapat berdasarkan hasil wawancara dan observasi langsung yang dilakukan dengan karyawan Masjid Cheng Hoo sehingga berdasarkan wawancara yang dilakukan juga dapat menunjang hasil penelitian tentang bagaimana implementasi sifat amanah yang sudah diterapkan oleh karyawan Masjid Cheng Hoo Surabaya.

\section{HASIL DAN PEMBAHASAN}

Mengenai sifat Amanah pada karyawan Masjid Cheng Hoo pada semua informan yang telah di wawancarai oleh peneliti merasakan hal sama, yaitu bekerja di masjid akan memiliki sifat amanah yang besar, dan tanggung jawab nya juga besar, Karena bertanggung jawab langsung dengan Allah SWT. Menurut bapak mintarjo:

"Amanah itu kan titipan, di dapat karna dia percaya kita, kalau dia gak percaya kita gak bakal di kasih amanah. Dia pecaya kita bahwa kita mampu melaksanakan dan mau melaksanakan, kalau mampu tapi gak mau ya gak bakal jadi amanah. Istilahnya sebuah kepercayaan harus kita laksanakan yang harus kita kerjakan sebaik-baiknya sesuai kesepakatan".

Indikator Amanah yang diterapkan dalam penelitihan ini adalah Tanggung Jawab, Transparan, dan Tepat janji. Tanggung jawab karyawan masjid tidak hanya menyelesaikan tugasnya melainkan ada tugas-tugas yang lain yang berhubungan dengan kemasjid'an harus di kerjakan tanpa melalaikan tugas utamanya.

Indikator ke dua yaitu Tepat janji, dalam setiap pekerjaan memiliki adanya perjanjian kerja yang memang harus sudah diterapkan dengan baik seesuai kebjakan lembaga atau yayasan yang besangkutan. Tepat janji dalam hal menyelesaikan tugas yang diberikan dengan tepat waktu Karena memang sudah menjadi tanggung jawab harus segera di selesaikan. Tepat janji dalam menghadiri rapat kerja juga sebagai 
contoh kecil dari makna tepat janji tersebut.

Indikator ke tiga yaitu transparansi, hal ini di jadikan indikator amanah oleh peneliti Karena transparansi akan menghilangkan rasa suudzon dan dapat menimbulkan rasa percaya yang akan dapat menjadikan rasa yang nyaman oleh sesama karyawan maupun jamaah. Sehingga Indikator amanah tersebut telah dilakukan oleh karyawan Masjid Cheng hoo dengan baik. Karyawan cheng hoo telah mengimplementasikan indikator amanah pada pekerjaannya.

Untuk memenuhi kebutuhan hidupnya, Ada dua orang karyawan yang memiliki kerja sampingan, dan dua orang karyawan yang lain menjadikan kerja di cheng hoo sebagai kerja utama untuk memenuhi kebutuhannya.

Menurut karyawan kerja di masjid harus ikhlas. Kerja di masjid bukan hanya mencari dunia saja, tetapi juga akhirat. Sehingga menurut karyawan masjid bekerja di masjid harus memiliki niat. Kebutuhan hidup akan tercukupi dengan sendirinya jika kita ikhlas dan mencari ridho Allah.

Ada pertanyaan yang diajukan seputar agama dalam Masjid Cheng Hoo yaitu mengenai adanya pengajian rutin di Masjid cheng hoo Surabaya, adanya pelatihan baca tulis Al-Qur'an, serta sikap ke Taqwaan karyawan saat bekerja di Masjid Cheng Hoo. Seluruh karyawan Masjid Cheng Hoo mengatakan bahwa tidak ada ada kajian rutin dan tidak ada wajib baca Al-Qur'an untuk karyawannya. Akan tetapi kajian itu ada untuk umum, sama hal nya dengan pelatihan baca tulis Al-Qur'an hanya untuk umum saja. Untuk kajian untuk umum dilaksanakan pada hari sabtu dan minggu di Masjid Cheng Hoo Surabaya.

Semua karyawan Masjid Cheng Hoo juga mengatakan bahwa bekerja di Masjid akan meningkatkan ke Taqwaan. Seperti hal nya yang di jelaskan oleh Bapak Hariono "Meningkatkan ke Taqwaan itu jelas, Karena lingkungannya kan berpengaruh, penghuninya bagus insyaallah penunjang juga".

Pertanyaan mengenai jiwa yaitu rasa ikhlas dalam mengerjakan pekerjaan, adanya mendapatkan pekerjaan tambahan dan ikhlas dalam menjalankan pekerjaan tambahan tersebut serta perasaan senang yang di miliki karyawan saat bekerja di Masjid Cheng Hoo Surabaya. Dari jawaban yang ada semua karyawan Masjid Cheng Hoo Surabaya bekerja di Masjid harus ikhlas, pada dasarnya untuk mencari ridho Allah. Semua karyawan juga mendapatkan tugas tambahan dan tiap orang pun berbeda-beda. Seperti informan 3 yaitu Mas Fuad beliau pernah mendapatkan tugas tambahan sepeti memimpin dzikir. Mas Fuad mengerjakan tugas tambahan tersebut dengan ikhlas, karena bagi Mas Fuad juga sudah biasa. Selain itu semua karyawan Masjid Cheng Hoo Surabaya juga mengatakan bahwa bekerja di 
Masjid mereka memiliki perasaan yang sangat senang sekali.

Pertanyaan mengenai Akal yaitu adanya fasilitas pelatihan kerja untuk karyawan, tepat waktunya karyawan dalam menyelesaikan tugas, dan cara penyelesaian tugas. Semua karyawan Masjid Cheng Hoo Surabaya mengatakan bahwa tidak ada pelatihan khusus untuk karyawan. Hal tersebut di dukung oleh pernyataan Bapak Mintarjo, Menurut Bapak Mintarjo "Tidak ada fasilitas pelatihan untuk karyawan, tetapi jika butuh tenaga akan dilatih". Selain itu karyawan Masjid Cheng Hoo sudah menjadawalkan pekerjaannya sehingga selalu tepat waktu. Hal tersebut juga di dukung oleh Bapak Mintarjo, menurut Bapak Mintarjo menjalankan tugas selalu tepat waktu Karena beliau sudah menjadwal pekerjaannya sehingga akan selesai sesuai deadline yang diberikan dan cara menyelesaikan tugasnya semua sudah tertata sehingga lebih mudah menyelesaikannya.

Pertanyaan mengenai Keturunan yaitu berapa sering mengajak anak di masjid dan mengajak anak untuk mengikuti kajian yang ada di Masjid, adanya pelatiha pola asuh anak serta adankah asuransi keluarga. Di Masjid Cheng Hoo tiga informan yang diwawacarai mengatakan bahwa masih belum menikah sehingga tidak menjawab pertanyaan mengenai hal tersebut. Berbeda dengan Bapak Hariono, beliau mengatakan bahwa sering kali mengajak anaknya untuk mengikuti kajian dan ke Masjid saat anak-anaknya libur.

Di Masjid Cheng Hoo tidak mengasuransikan karyawan beserta kelvarga sehingga karyawan ada yang mengasuransikan dirinya dan ada juga yang tidak mengasuransikan. Hal tersebut di dukung oleh pernyataan Mas Fuad "asuransi untuk karyawan dan keluarga belum ada, dan saya juga belum ikut"

Pernyataan mengenai harta yaitu adakah tambahan kompensasi selain gaji yang diberikan kepada karyawan serta adakah tambahan kompensasi untuk karyawan yang berprestasi. Menurut tiga karyawan Masjid Cheng Hoo tambahan kompensasi selain gaji itu tidak ada, yang ada hanya tunjangan hari raya saja. Berbeda dengan Mas Fuad yang tiap hari minggu mendapatkan tambahan kompensasi dari pekerjaan tambahan yang ada. Serta kompensasi karyawan yang berprestasi juga tidak ada. Menurut Mas Fuad "Tambahan gaji untuk karyawan berprestasi itu belum ada". Hal tersebut juga di dukung oleh pernyataan Bapak Hariono, menurut Bapak Hariono "Tambahan gaji untuk karyawan berprestasi itu tidak ada, jika ada yang bagus gajinya akan dinaikan".

\section{SIMPULAN}

Kesimpulan dari penelitian mengenai Implementasi sifat amanah karyawan Masjid Cheng Hoo Surabaya dalam mewujudkan kesejahteraan prespektif maqashid Syariah: 
a) Implementasi sifat amanah pada Karyawan Masjid Cheng Hoo Surabaya sudah diterapkan dengan baik.

b) Indikator Amanah (Tanggung jawab, transparansi, dan tepat janji) sudah diterapkan dengan baik oleh karyawan Masjid Cheng Hoo Surabaya. Ketiga indikator tersebut dapat dilihat berdasarkan hasil wawancara secara langsung dengan karyawan Masjid tersebut.

c) Indikator Ekonomi yang diterima oleh karyawan cheng hoo sudah mencukupi Karena bagi karyawan masjid cheng hoo yang utama mencari ridho Allah bukan duniawi saja.

d) Indikator maqashid Syariah

1) Dari segi Memelihara Agama, di Masjid Cheng Hoo tidak mengadakan kajian untuk karyawan dan karyawan masjid memiliki sikap ketaqwaan Karena berada pada lingkungan Masjid.

2) Dari segi memelihara Jiwa, karyawan ikhlas dalam bekerja di masjid cheng hoo Karena niat utama yaitu mencari ridho Allah.

3) Dari segi memelihara Akal, karyawan Masjid Cheng Hoo selalu melaksanakan tugasnya dengan tepat waktu dan di Masjid Cheng Hoo sendiri tidak ada pelatihan kerja untuk karyawannya.

4) Dari segi keturunan, karyawan Masjid Cheng hoo dan keluarganya tidak mendapatkan asuransi.
5) Dari segi Jiwa, karyawan Masjid Cheng Hoo tidak mendapatkan kompensasi / insentif lainnya hanya tunjangan hari raya saja dan tidak mendapatkan kompensasi untuk karyawan yang berprestasi.

\section{DAFTAR PUSTAKA}

Abiyoga, Firdaus Arfianandy.

2014."Implementasi sifat amanah pengelola Koperasi Pondok Pesantren Qomaruddin Desa Sampurnan Kecamatan Bungah Kabupaten Gresik". Skripsi tidak diterbitkan. Universitas Airlangga.

Afifuddin dan Beni Ahmad Saebani. 2009. Metodelogi Penelitian Kualitatif.Bandung: Pustaka Setia.

Basir, Bartos. 1990. Manajemen Sumber Daya Manusia. Jakarta: Bumi Aksara.

Bungin, Burhan. 2008. Penelitian Kualitatif. Jakarta: Kencana

Departemen Pendidikan dan Kebudayaan. 1996. Kamus Besar Bahasa Indonesia. Jakarta: Balai Pustaka

Duhriah. 2015. Tingkatan-Tingkatan Maqashid Al-Syariah: alDharruruyyat, al Hajiyyat, dan al-Tahsiniyyat. Jurnal Vol. 01 No. 1 Januari-Juni 2015 hal 191-210. Enggardini, Rohma Vihana. 2016. "Kesejahteraan Karyawan Perspektif Maqashid Syariah pada Pusat Penelitian Kopi dan Kakao Indonesia". Skripsi tidak diterbitkan. Universitas Airlangga. 
Fauzia, Abdul Kadir. 2014. Prinsip Dasar Ekonomi Islam. Jakarta : Prenadamedia Group.

Ghani, Muhammad llyas Abdul. 2005. Sejarah Masjid Nabawi. Indonesia:Depag.

Handoko, T. Hani, 2000. Manajemen Sumber Daya Manusia. Yogyakarta: BPFE

Hasibuan, Malayu S.P. 2005. Manajemen Sumber Daya Manusia. Jakarta: Bumi Aksara.

Herianingrum, Sri. 2015. Implementasi Nilainilai Amanah pada karyawan Hotel Darussalam Pondok Pesaantren Gontor di Ponorogo. Jurnal. Vol.1 (1)

Husna, Amalia. 2009. Amanah (Terpercaya), Cetakan Pertama. Jakarta Timur: Inti Medina.

Kusumawardhani, siska hapsari. 2011. Masjid Besar Kecamatan Depok Sleman Di Yogyakarta. Skripsi. FT, Pend. Arsitek, Universitas Atma Jaya Yogyakarta.

Kurniawan, yamsul. 2014. Masjid dalam Lintas Sejarah Umat Islam. Journal oflslamic Studies. Vol.4 (2).

Merchant, Van der Stede. 2014. Sistem Pengendalian Manajemen: Pengukuran Kinerja, Evaluasi dan Insentif. Jakarta: Salemba Empat.

Moleong, Lexy J. 2000. Metode Penelitian Kualitatif. Bandung: PT. Remaja Rosdakarya

Nawawi Syaifuddin. 2008. Memberdayakan Masjid Sebagai
Pusat Pembinaan Ekonomi

Umat. Makalah Tidak

Dipublikasikan. Suraba: DMI Jatim.

Nazir, Mohammad. 2003. Metode Penelitian. Jakarta: Ghalia Indonesia.

Paksi, Diera G. 2011. Implementasi Amanah dalam Pemasaran Internal danDampaknya bagi Niat Wali Murid untuk Melanjutkan Studi Anaknya di Sekolah Dasar Islam AlAzhar Surabaya. Penelitian Tidak Dipublikasikan.Surabaya: Fakultas Ekonomi Universitas Airlangga.

Piti. 2001. Laksamana Haji Muhammad Cheng Hoo Bahariwan Kebanggaan Umat Islam.Press Release

Siagang, Sondang. 2004. Manajemen Abad 21 . Jakarta: Bumi Aksara.

Simamora, Henry. 2005. Membuat Karyawan Lebih Produktif dalam Jangka Panjang (Manajemen SDM). Yogyakarta: STIE YKPN.

Setiawan, Guntur. 2004. Impelemtasi dalam Birokrasi Pembangunan Balai.Jakarta: Pustaka.

Sugiyono. 2010. Metode Penelitian Kuantitatif Kualitatif dan R\&D.Bandung:Alfabeta

Sumandi, Suryabrata. 1994. Metodologi Penelitian. Jakarta: Rajawali

Sumarsono, Sonny. 2003. Ekonomi Manajemen Sumberdaya Manusia danKetenagakerjaan. Yogyakarta: Graha llmu. 
Astuti, et al/Jurnal Ekonomi Syariah Teori dan Terapan Vol. 6 No. 5 Mei 2019: 1030-1041; SIFAT AMANAH KARYAWAN MASJID CHENG HOO SURABAYA

Usman, Nurdin. 2002. Konteks

Implementasi Berbasis Kurikulum.

Jakarta: $\quad$ Grasindo.

Veithzal, Rivai. 2004. Manajemen Sumber

Daya Manusia untuk

Perusahaan.Jakarta: Raja Grafindo

Persada.

Wulandari, Nanada Rizki. 2013.

"Implementasi Nilai-Nilai Amanah

Tim Pengajae Divisi Kajian dan

Diklat Masjid Al-Akbar Surabaya".

Skripsi tidak diterbitkan. Universitas

Airlangga.

Yani, Ahmad.2007. Panduan Mengelola

Masjid. Jakarta: Pustaka Lebah

Zarkhoviche, Baha. 2017. Jejak-Jejak Emas

Laksamana Cheng

Hoo.Yogyakarta:Araska 